\title{
Testing of microsatellite multiplexes for individual identification of Cape Parrots (Poicephalus robustus): paternity testing and monitoring trade
}

\author{
Willem G Coetzer $^{1}{ }^{\text {, }}$, Colleen T Downs ${ }^{1}{ }^{\text {, }}$ Mike R Perrin ${ }^{1}{ }^{\text {, }}$ Sandi Willows-Munro ${ }^{\text {Corresp. }} 1$ \\ ${ }^{1}$ School of Life Science, University of KwaZulu-Natal, Pietermaritzburg, KwaZulu-Natal, South Africa \\ Corresponding Author: Sandi Willows-Munro \\ Email address: willows-munro@ukzn.ac.za
}

Background. Illegal trade in rare wildlife species is a major threat to many parrot species around the world. Wildlife forensics plays an important role in the preservation of endangered or threatened wildlife species. Identification of illegally harvested or traded animals through DNA techniques is one of the many methods used during forensic investigations. Natural populations of the South African endemic Cape Parrot (Poicephalus robustus) are negatively affected by the removal of eggs and chicks for the pet trade.

Methods. In this study, 16 microsatellite markers specifically designed for the South African endemic Cape Parrot (Poicephalus robustus) are assessed for their utility in forensic casework. Using these 16 loci the genetic diversity of a subset of the captive Cape Parrot population was also assessed and compared to three wild Cape Parrot populations.

Results. It was determined that the full 16 locus panel has sufficient discriminatory power to be used in parentage analyses and can be used to determine if a bird has been bred in captivity and so can be legally traded or if has been illegally removed from the wild. In cases where birds have been removed from the wild, this study suggests that a reduced 12 locus microsatellite panel has sufficient power to assign confiscated birds to geographic population of origin.

Discussion. The level of genetic diversity observed within the captive Cape Parrot population was similar to that observed in the wild populations, which suggests that the captive population is not suffering from decreased levels of genetic diversity. The captive Cape Parrots did however have double the number of private alleles compared to that observed in the most genetically diverse wild population. This is probably due to the presence of rare alleles present in the founder population, which has not been lost due to genetic drift, as many of the individuals tested in this study are F1 to F3 wild descendants. The results from this study provide a suit of markers that can be used to aid conservation and law enforcement authorities to better control legal and illegal trade of this South African endemic. 
1 Title: Testing of microsatellite multiplexes for individual identification of Cape Parrots

2 (Poicephalus robustus): paternity testing and monitoring trade

3 Authors: Willem G. Coetzer, Colleen T. Downs, Mike R. Perrin and Sandi Willows-Munro*

4 School of Life Sciences, University of KwaZulu-Natal, P/Bag X01, Scottsville, Pietermaritzburg, $5 \quad 3209$

6 Running title: Paternity and forensic analysis of the Cape Parrot

$7 \quad *$ To whom correspondence should be addressed:

8 Dr Sandi Willows-Munro

9 School of Life Sciences

10 University of KwaZulu-Natal, Pietermaritzburg Campus

11 John Bews A building, Rm 218

12 Phone: +27 (33) 2605436

13 Fax: +27 (33) 2606127

14 Email: willows-munro@ukzn.ac.za

15 
17 Abstract

18 Background. Illegal trade in rare wildlife species is a major threat to many parrot species around the world. Wildlife forensics plays an important role in the preservation of endangered or threatened wildlife species. Identification of illegally harvested or traded animals through DNA techniques is one of the many methods used during forensic investigations. Natural populations of the South African endemic Cape Parrot (Poicephalus robustus) are negatively affected by the removal of eggs and chicks for the pet trade.

Methods. In this study, 16 microsatellite markers specifically designed for the South African endemic Cape Parrot (Poicephalus robustus) are assessed for their utility in forensic casework. Using these 16 loci the genetic diversity of a subset of the captive Cape Parrot population was also assessed and compared to three wild Cape Parrot populations.

Results. It was determined that the full 16 locus panel has sufficient discriminatory power to be used in parentage analyses and can be used to determine if a bird has been bred in captivity and so can be legally traded or if has been illegally removed from the wild. In cases where birds have been removed from the wild, this study suggests that a reduced 12 locus microsatellite panel has sufficient power to assign confiscated birds to geographic population of origin.

Discussion. The level of genetic diversity observed within the captive Cape Parrot population was similar to that observed in the wild populations, which suggests that the captive population is not suffering from decreased levels of genetic diversity. The captive Cape Parrots did however have double the number of private alleles compared to that observed in the most genetically diverse wild population. This is probably due to the presence of rare alleles present in the founder population, which has not been lost due to genetic drift, as many of the individuals tested in this study are F1 to F3 wild descendants. The results from this study provide a suit of markers that can be used to aid conservation and law enforcement authorities to better control legal and illegal trade of this South African endemic. 


\section{Introduction}

The illegal wildlife trade includes the buying and selling of any wildlife product that has been captured alive, poached, and used as food, medicine, pets and trophies (TRAFFIC 2008). The illegal trade in wildlife has a negative impact on wildlife and conservation programs worldwide (Alacs et al. 2010). The exact value of the illegal wildlife trade is unknown, but current estimates suggest that illegal transactions involving wildlife, and their products, is a multibillion US dollar enterprise (Broad et al. 2002; Interpol 2014). This is particularly true for rare bird species, which are highly sought after (Cooney \& Jepson 2006; White et al. 2012). Parrots (order Psittaciformes) are extremely popular as pets and have the highest reported trade figures among all traded avian orders (Bush et al. 2014). Of particular concern are the rare and enigmatic species as half of the world's threatened or near-threatened parrot species are impacted by illegal trade (Pain et al. 2006). African parrot species are increasingly becoming targets for trade. For example, in China a quarter of all imported parrots originated from South Africa (Li \& Jiang 2014). To date CITES has classified South Africa as a major importer and exporter of legally and illegally obtained birds (Warchol 2004) and is regarded as the hub of both legal and illegal wildlife trade in the region (Wynberg 2002).

Captive breeding of exotic birds is a plausible alternative to sourcing wild animals, and it has been shown to be a viable practice (Pires 2012). Breeding of wildlife in captivity is, however, not always an alternative to wild harvesting, as there will always be a demand for new breeding stock from the wild (Nogueira \& Nogueira-Filho 2011; Bush et al. 2014). The creation of self-sustaining captive populations, which resembles the wild genetic lineages as closely as possible, should be one of the main aims of captive breeding programs if reintroductions are proposed (Frankham 2008; Robert 2009). Regular assessments of the genetic fitness of captive populations are therefore important to ensure healthy populations exist for possible reintroductions. The legitimacy of some 'captive-bred' animals are also a concern, as it has been suggested that some breeding facilities produce more 'captive-bred' animals than is plausible (Lyons \& Natusch 2011; White et al. 2012). It is therefore imperative to monitor the legal trade of alleged captive bred birds to identify possible illegal activities.

Molecular forensic methods are widely used to identify suspected illegally obtained wildlife or wildlife products (Comstock et al. 2003; Gupta et al. 2005; Lorenzini 2005; Dawnay 
et al. 2009; Lorenzini et al. 2011; Coghlan et al. 2012; White et al. 2012; Mondol et al. 2014; Gonçalves et al. 2015; Presti et al. 2015). One of the most useful molecular forensic tools are genetic fingerprinting using microsatellite markers. These markers have been used to identify legally, and illegally, traded birds when a sufficient reference database is available (White et al. 2012; Presti et al. 2015). It is necessary to consider the genetic sub-structuring within a species if the re-introduction of confiscated animals are considered, as the subpopulations could have acquired habitat specific fitness (for example pathogen resistance; Boyce et al. 2011). It is important, from a conservation viewpoint, to preserve genetically distinct or evolutionary significant populations (Johnson 2000). The use of microsatellite data to assign confiscated wildlife to their area of origin is a well-known technique used in wildlife forensic and conservation sciences (Manel et al. 2002; White et al. 2012; Mondol et al. 2014; Presti et al. 2015). For example, Presti et al. (2015) was able to assign 24 confiscated Hyacinth Macaw chicks to their populations of origin based on Bayesian clustering analysis using 10 microsatellite loci and White et al. (2012) were able to identify the kinship and area of origin of a White-tailed Black Cockatoo using 20 microsatellite loci and kinship analyses.

Several factors need to be considered when selecting a microsatellite panel for forensic studies. The quality of the data obtained from a set of markers should be assessed by considering the occurrence of genotyping errors such as null alleles and missing data which can lead to biased estimations of genetic diversity and false parentage assignments (Dakin \& Avise 2004). Additionally, the level of informativeness of each marker should be assessed, focusing on the level of variation and the discriminatory power of each locus (Rosenberg et al. 2003). For more information on molecular methods in wildlife forensics and microsatellite null alleles see Alacs et al. (2010) and Dakin \& Avise (2004).

Numerous well-established methods are available to assess the informativeness of genetic markers namely, the polymorphic information content (PIC) estimate (Botstein et al. 1980), the probability of identity (PID; Taberlet \& Luikart 1999; Waits et al. 2001); and the probability of exclusion (PE; Fung et al. 2002). The $P_{\mathrm{ID}}$ and $P_{\mathrm{E}}$ estimates are well-established methods for assessing the ability of molecular markers to distinguish between individuals (Taberlet \& Luikart 1999; Fung et al. 2002). 

parrot species found in the South African mistbelt forests (Wirminghaus 1997; Taylor 2014), with fewer than 1600 individuals left in the wild (Downs et al. 2014). It has been suggested that the Cape Parrot is under tremendous pressure, not only due to habitat fragmentation, but also due to the illegal harvesting of wild birds and eggs for the pet trade (Wirminghaus et al. 1999; Martin et al. 2014). The Cape Parrot is currently still observed as a subspecies of Poicephalus robustus and I therefore not classified by the International Union for Conservation of Nature (IUCN) or Convention on International Trade in Endangered Species of Wild Fauna and Flora (CITES) as endangered or threatened. Recent genetic work has, however, shown that the Cape Parrot should be elevated to species status (Coetzer et al. 2015), separate from the more widely distributed Grey-headed Parrot (Poicephalus fuscicollis suahelicus).

Cape Parrots have been successfully bred in captivity for a number of years, although it is a difficult practice with low breeding success among wild-caught breeding pairs (Wirminghaus et al. 1999). Captive breeding facilities provide the pet trade with legally obtained animals, and may also serve as source populations if future reintroductions to natural habitats are needed (Storfer 1999; Williams \& Hoffman 2009; Pires 2012). The occurrence and accumulation of deleterious mutations, as well as the effects of genetic adaptation to captivity (Williams \& Hoffman 2009) are major issues observed in captive populations. It was recently observed that the current Cape Parrot population shows signs of genetic sub-structuring, with three genetic clusters which are geographically correlated along the Cape Parrot distribution range (Coetzer 2015). It is therefore important to maintain captive populations which are genetically similar to these three genetic lineages if future reintroductions are needed. Proper studbook keeping and managing of the captive populations are therefore essential for maintaining healthy captive bred wildlife populations (Ferrie et al. 2013). The regional Cape Parrot studbook currently holds records of 341 Cape Parrots, 216 extant (Wilkinson 2015). The studbook is, however, currently lacking many records due to many breeders showing reluctance in sharing information with regards to their Cape Parrot stocks (Wilkinson, pers. com.). markers previously designed specifically for Cape Parrots (Pillay et al. 2010) was conducted to determine their utility in forensic analyses. A subset of these 16 loci were previously used in a 
134 higher-level taxonomic analysis of Poicephalus parrots (Coetzer et al. 2015) and all 16 loci were 135 used in a phylogeographic assessment of the Cape Parrot (Coetzer 2015). Second, the utility of 136 these 16 loci for use in assigning confiscated wild-caught birds to their area of origin was tested 137 through a Bayesian assignment method. The approach outlined in this study will assist law 138 enforcement and conservation authorities with the return of illegally harvested Cape Parrots to 139 the wild. It is known that the genetic variation of populations in captivity can change markedly 140 from the wild populations (Hindar et al. 1991; Lynch \& O'Hely 2001), which can have serious 141 implications when reintroductions are considered. It is therefore vital to assess the genetic 142 variation and structure of the captive Cape Parrot population. Third, the genetic differentiation 143 between the three wild Cape Parrot populations identified by Coetzer (2015) and the captive 144 population was assessed using 16 microsatellite loci. These results will aid in the management of 145 the captive population and to ensure that the captive population can be self-sustaining with 146 minimal or no supplementation from the wild.

\section{Material and Methods}

\section{Ethics}

Ethical clearance for this study was received from the University of KwaZulu-Natal Animal Ethics sub-committee (Ref numbers: 074/13/Animal, 017/14/Animal, 042/15/Animal). All sampling procedures followed the criteria laid out by this committee.

\section{Sampling and DNA extraction}

153

154

155

156

157

158

159

160

161

162

Samples were collected from 76 captive Cape Parrots (Supplementary Table 1). This includes samples taken from one international and five South African breeding facilities. The captive specimens included in this study comprise $22.3 \%$ of the Cape Parrot regional studbook (Wilkinson 2015). The majority of these samples were sourced from one breeding facility, which holds the largest captive Cape Parrot breeding populations in the world. Five of the specimens included in this study were wild caught birds that were recently introduced into the captive breeding program. These five birds originated from the KwaZulu-Natal (KZN) Province. To test the utility of the molecular markers, captive birds with known pedigree were included. Both parents of 31 specimens were sampled, with only the sire sampled for seven of the captive bred birds (Supplementary Table 1). 
Whole blood was collected from 45 captive Cape Parrots using Whatman ${ }^{\mathrm{TM}}$ FTA $^{\mathrm{TM}}$ Elute

164

165

166

167

168

169

170

171

172

173

174

175

176

177

178

179

180

181

182

183

184

185

186

187

188

189

190

191

cards and was stored at room temperature in a dark cool storage area. Seventeen samples were whole blood stored in absolute ethanol at $-20^{\circ} \mathrm{C}$. Samples were also collected from deceased birds provided by two breeding facilities $(\mathrm{n}=14)$. Biopsies of $5 \mathrm{~mm}$ x $5 \mathrm{~mm}$ were collected from each carcass and stored in absolute ethanol at $-20{ }^{\circ} \mathrm{C}$.

DNA extraction from the Whatman ${ }^{\mathrm{TM}}$ FTA $^{\mathrm{TM}}$ Elute cards was performed following the manufacturer's protocols. The DNA extraction from the tissue and whole blood stored in absolute ethanol was performed with the NucleoSpin ${ }^{\circledR}$ Tissue kit (Macherey-Nagel), following the manufacturer's protocols. All DNA extracts were stored at $-20^{\circ} \mathrm{C}$. DNA quantity was established via NanoDrop ${ }^{\circledR}$ ND-1000 Spectrophotometer (Thermo Fisher Scientific, Delaware USA) analysis.

To assess any genetic differences between captive-bred and wild Cape Parrots, 85 genotypes from wild Cape Parrot populations were taken from Coetzer (2015). This study assessed the phylogeographic relationships between wild Cape Parrot populations. Strong genetic sub-structuring was observed, with three distinct genetic clusters linked to three geographical regions within the Cape Parrot distribution range (Coetzer 2015). The wild data set consisted of 52 genotypes from the South genetic cluster (Eastern Cape region), 19 from the Central cluster (KZN region) and five genotypes from the North cluster (Limpopo region). Details on these specimens are provided in Supplementary Table 2.

\section{Microsatellite amplification}

The 16 microsatellite loci selected for this study were specifically developed for use in Cape Parrots (Pillay et al. 2010). The markers were divided into six multiplex sets (Multiplex 1: Prob06, Prob15 and Prob26; Multiplex 2: Prob30 and Prob36; Multiplex 3: Prob18, Prob25 and Prob31; Multiplex 4: Prob01, Prob09 and Prob17; Multiplex 5: Prob23 and Prob28; Multiplex 6: Prob29, Prob34 and Prob35). In-silico testing of all multiplexes were done prior to PCR amplification to test for the presence of primer dimers and hairpin structures using the program AutoDimer v1 (Vallone \& Butler 2004). The selected multiplex combinations did not show any signs of primer dimers or hairpin structures among the primer pairs. The forward primer in each microsatellite pair was fluorescently labelled on the 5' end. The KAPA2G Fast 
192 Multiplex mix (KAPA Biosystems) was used for all amplifications, with each PCR reaction 193 mixture consisting of: 2-60 ng template DNA, $5 \mu$ KAPA2G Fast Multiplex mix (KAPA 194 Biosystems), $0.2 \mu \mathrm{M}$ of each primer and $\mathrm{dH}_{2} \mathrm{O}$ to give a final reaction volume of $10 \mu \mathrm{l}$. The

195 196

197

198

199

200

201

202

203

204

205

206

207

208

209

210

211

212

213

214

215

216

217

218

219

220 annealing temperature prescribed by the KAPA2G Fast Multiplex kit's manufacturers was initially tested and provided positive results for all multiplex sets. The PCR cycling conditions consisted of an initial denaturation step for $3 \mathrm{~min}$ at $94{ }^{\circ} \mathrm{C}$ followed by 30 cycles at $94{ }^{\circ} \mathrm{C}$ for 30 $\mathrm{s}, 60{ }^{\circ} \mathrm{C}$ for $30 \mathrm{~s}, 72{ }^{\circ} \mathrm{C}$ for $30 \mathrm{~s}$, and a final extension step for $5 \mathrm{~min}$ at $72{ }^{\circ} \mathrm{C}$. The whole PCR setup, excluding the DNA addition step, were performed in a DNA free area.

The amplified PCR products were sent to the Central Analytical Facility at Stellenbosch University, South Africa, for fragment analysis, using a standard ROX 500 internal size standard. The software package GeneMarker ${ }^{\circledR}$ v2.4.0 (Soft Genetics) was used for all genotype scoring. We reamplified $20 \%$ of the data set to check for genotype consistency.

Data analysis

\section{Evaluating best set of microsatellite loci}

The Expectation Maximization algorithm (EM) for detection of null allele frequencies was used as implemented in the software program FreeNA (Chapuis \& Estoup 2007). To assess the informativeness of each locus, the polymorphic information content (PIC) and the allelic richness (Ar) of each locus was calculated using Cervus (Kalinowski et al. 2007) and FSTAT (Goudet 2001) respectively. Per marker PIC values higher than 0.6 are generally seen as highly informative (Mateescu et al. 2005). The rarefaction method was followed for the Ar estimation, to account for differences in sample size. The probability of identity $\left(P_{\mathrm{ID}}\right)$ and probability of exclusion (one parent known, $P_{\mathrm{E} 2}$ ) were estimated in GenAlEx (Peakall \& Smouse 2012) to evaluate the discriminatory power of each locus. The combined $P_{\mathrm{ID}}$ and $P_{\mathrm{E} 2}$ values was also calculated. Deviations from Hardy-Weinberg equilibrium (HWE) was estimated using Genepop v4.2 (Rousset 2008). (Table 1). A score of one (excellent) to 16 (poor) was given to each locus for each of these five estimates, with a minimum of 5 (highly informative) to a maximum of 80 (highly uninformative). Eight microsatellite panels were then assembled by selecting the highest ranking 
221 loci for each panel, containing 9 to 16 loci each (Supplementary Table 3). Each of these eight

222 panels were tested in the subsequent parentage and assignment analyses.

\section{Parentage testing of captive population}

224 The eight selected microsatellite panels were evaluated by testing the accuracy of each panel for parentage assignments, using captive specimens with both known and unknown pedigrees. For this analysis, the full-pedigree maximum likelihood method implemented in Colony v2.0.4.6 (Jones \& Wang 2010) was used. This program compensates for genotyping errors and null alleles (Wang 2004) and has been used previously to identify parentage in captive (Ferrie et al. 2013; Loughnan et al. 2015) and wild vertebrate populations (Masello et al. 2002; Riehl 2012; Bergner et al. 2014). The offspring data set consisted of 38 individuals. For seven of these only the paternal parent was known. A monogamous mating system with no inbreeding was selected, using the full-likelihood method. A medium run length with no sibship prior was selected. The marker type and null allele frequencies for each locus was uploaded with an error rate of 0.02 as suggested by Wang (2004). We uploaded the genotypes of 38 offspring, 30 paternal candidates and 21 maternal candidates, with the probability of the sire or dam included in the data set at 0.75 and no paternal or maternal exclusion information.

Power of microsatellite panel to detect origin of illegally traded birds

238

239

240

241

242

243

244

A partial Bayesian exclusion approach (Rannala \& Mountain 1997) as implemented in GenClass2 (Piry et al. 2004) was used to further assess the eight microsatellite panels. This method estimates the likelihood that a test sample belongs to one of the reference populations provided for analysis and calculates a sample exclusion probability for each of the reference populations (Ogden \& Linacre 2015). The use of assignment methods to identify the population or area of origin of confiscated wildlife is a well-known tool in wildlife forensics (Alacs et al. 2010; Ogden \& Linacre 2015). The partial Bayesian assignment analysis implemented in GeneClass2 is a well-established method for assignment of specimens to their population of origin (Primmer et al. 2000; Grobler et al. 2005; Pruett et al. 2010). All wild born individuals were excluded from the captive population reference data set. To simulate an assignment study, six captive bred and six wild caught individuals were selected at random for the "samples to be assigned" data set. The captive population from the current study and the three wild populations 
250 from Coetzer (2015) were used as reference populations. The 12 individuals selected for the

251 "samples to be assigned" data set were excluded from these data sets. The Bayesian method from

252 Rannala \& Mountain (1997) was followed, with probability computation using Monte-Carlo

253 resampling and the simulation algorithm from Paetkau et al. (2004). The number of simulated

254 individuals were set at 100000, with the Type I error set at 0.01 and the assignment threshold at

255 0.05. These parameters were used for each of the eight microsatellite panels.

256 Captive vs wild Cape Parrots

257 The genetic diversity of the captive bred sample group was compared to the three wild Cape

258 Parrot populations identified in the recent phylogeographic study (Coetzer 2015). Values

259 compared included the average number of alleles $\left(\mathrm{N}_{\mathrm{A}}\right)$, number of private alleles $\left(\mathrm{P}_{\mathrm{A}}\right)$, observed

260 heterozygosity $\left(H_{\mathrm{O}}\right)$ and unbiased expected heterozygosity $\left(u H_{\mathrm{E}}\right)$ estimated in GenAlEx,

261 inbreeding coefficient ( $\mathrm{F}_{\mathrm{IS}}$ ) using Genepop v4.2 (Rousset 2008) and allelic richness (Ar) using

262 rarefaction in FSTAT (Goudet 2001). A Wilcoxon signed-ranked test was performed to assess

263 the level of genetic differences between the captive population and the three wild populations

264 using the per locus estimates for each of the $\mathrm{N}_{\mathrm{A}}, H_{\mathrm{O}}, u H_{\mathrm{E}}, F_{\mathrm{IS}}$ and Ar estimates. Pairwise $F_{\mathrm{ST}}$

265 values and analysis of molecular variance (AMOVA) were estimated to assess if the captive

266 population constitutes a separate genetic unit using GenAlEx. A Bonferroni correction was

267 implemented to all $p$-values to correct for problems with multiple testing (Rice 1986). In this

268 analysis, the five wild born individuals were removed from the captive data set.

\section{Results}

\section{Marker analysis}

271 For this study, 76 captive Cape Parrots were successfully genotyped across 16 microsatellite loci.

272 Loci amplified across a range of DNA template concentrations, with low template concentration

$273(2-5 \mathrm{ng} / \mathrm{ul})$ successfully amplifying with minimal signs of allelic dropout ( $<3 \%$ over all loci).

274 The replicate genotypes did not show any signs of discrepancies. Co-amplification of each

275 multiplex was also highly successful, with the most amplification failures (4 of 76) observed for

276 the locus with the largest bp size (Prob17). The data set contained less than 1 missing data, with

277 a mean null allele frequency over all loci and samples of 0.039 . The per locus null allele

278 frequencies ranged from 0 to 0.186 (Table 1). Only two loci showed null allele frequencies 
279 above $0.1($ Prob15, $\mathrm{Na}=0.186 ;$ Prob36, $\mathrm{Na}=0.125)$. The mean number of alleles per locus

280 varied greatly among loci, ranging from 1.75 (Prob36) to 17 (Prob17) alleles. A large difference

281 in allelic richness (Ar) values were observed across the loci, with values ranging from 2

282 (Prob36) to 22 (Prob17). Seven loci showed high levels of heterozygosity (Table 1), with

283 negative $\mathrm{F}_{\mathrm{IS}}$ values. Only two loci showed signs of heterozygote deficiency $\left(\right.$ Prob09, $\mathrm{F}_{\mathrm{IS}}=0.439$;

284 Prob36, $\left.\mathrm{F}_{\mathrm{IS}}=0.471\right)$. Fourteen of the 16 loci were moderately to highly informative, with

285 polymorphic information content (PIC) values ranging from 0.415 (Prob29) to 0.888 (Prob17).

286 Only two loci (Prob35 and Prob36) were identified as uninformative (PIC < 0.3; Table 1). The

287 probability of identity $\left(P_{\mathrm{ID}}\right)$ values ranged from 0.019 (Prob17) to 0.591 (Prob36). A combined

$288 \mathrm{P}_{\mathrm{ID}}$ over all 16 loci was calculated as 1.831E-13 following the product rule. The probability of

289 exclusion $\left(P_{\mathrm{E} 2}\right)$ ranged from 0.658 (Prob17) to 0.032 (Prob36), with the combined $\mathrm{P}_{\mathrm{E} 2}$ at 0.995.

290 It was observed that the $P_{\mathrm{ID}}$ and $P_{\mathrm{E} 2}$ values improved as the number of loci analysed increase

291 (Figure 1). Five of the 16 loci significantly deviated from Hardy-Weinberg equilibrium (Prob09,

292 Prob15, Prob28, Prob30, Prob36), following Bonferroni correction ( $p$-value $<0.003)$. Of the

293120 per locus comparisons made during the linkage disequilibrium (LD) analysis, more than half 294 of the locus pairs showed signs of LD (52.5\%). 
296 Table 1. Primer details and genetic diversity estimates per locus as calculated from the captive Poicephalus robustus data set used in 297 the current study. The standard error for the average number of alleles is provided in parentheses. The values in superscript indicates 298 the locus' rank for the specific measure $(1=$ excellent and $16=$ poor $)$. It should be noted that Prob15 is reportedly Z-linked (Pillay et 299 al. 2010) which could influence the null allele frequency.

\begin{tabular}{|c|c|c|c|c|c|c|c|c|c|c|}
\hline Locus & Primer sequence $\left(5^{\prime}-3^{\prime}\right)$ : & $\begin{array}{c}\text { Average } \\
\text { number of } \\
\text { alleles }\left(N_{\mathrm{A}}\right)\end{array}$ & $\begin{array}{l}\text { Allelic } \\
\text { richness } \\
\text { (Ar): }\end{array}$ & $\begin{array}{l}\text { Probability } \\
\text { of identity } \\
(P \text { ID): }\end{array}$ & $\begin{array}{c}\text { Probability } \\
\text { of exclusion } \\
\text { (one parent } \\
\text { known; } P_{\mathrm{E} 2} \text { ) }\end{array}$ & $\begin{array}{l}\text { Polymorphic } \\
\text { information } \\
\text { content } \\
\text { (PIC): }\end{array}$ & $\begin{array}{l}\text { Null Allele } \\
\text { Frequency } \\
\text { (Na): }\end{array}$ & $\begin{array}{l}\text { Inbreeding } \\
\text { coefficient } \\
\left(F_{\text {Is }}\right) \text { : }\end{array}$ & $\begin{array}{c}\text { Hardy- } \\
\text { Weinberg } \\
\text { deviation }(p- \\
\text { value) } \\
\end{array}$ & Locus rank: \\
\hline Prob17 & $\begin{array}{l}\text { F: TGAACATGACTTATTTGTCTAGTCATACCTAATC } \\
\text { R: TTCCAAGGAGTAATATACAGATAATTGCTTCTAC }\end{array}$ & ${ }^{17(3.559)}$ & 221 & $0.018^{1}$ & $0.658^{1}$ & $0.888^{1}$ & $0.022^{3}$ & 0.017 & 0.045 & 1 \\
\hline Prob31 & $\begin{array}{l}\text { F: GCTGCAGTACAGGCAGTCTTTG } \\
\text { R: CCCATGGCAGAAATTACAGTGA }\end{array}$ & $5.25(1.109)$ & $6.997^{5}$ & $0.08^{2}$ & $0.404^{2}$ & $0.746^{3}$ & $0.00^{1}$ & -0.058 & 0.096 & 2 \\
\hline Prob26 & $\begin{array}{l}\text { F: GATCCCCAAAACAGATGAGTCT } \\
\text { R: GTTTCTTGATTCAGATTGGAGGCTGATG }\end{array}$ & $7.25(1.436)$ & $9.877^{3}$ & $0.088^{4}$ & $0.370^{4}$ & $0.723^{4}$ & $0.00^{1}$ & -0.109 & 0.188 & 3 \\
\hline Prob30 & $\begin{array}{l}\text { F: ACACTGAACCATGTCACACAAG } \\
\text { R: GATCAGAAGGCTGCTTTGC }\end{array}$ & $6(0.707)$ & $5.997^{8}$ & $0.081^{3}$ & $0.397^{3}$ & $0.751^{2}$ & $0.037^{4}$ & 0.044 & $0.0001^{*}$ & 4 \\
\hline Prob23 & $\begin{array}{l}\text { F: CACCAGTCATGACAGATAAT } \\
\text { R: AGTATAAATTCAGCCTAGTTATGT }\end{array}$ & $5(1.08)$ & $5.997^{7}$ & $0.106^{5}$ & $0.341^{5}$ & $0.707^{5}$ & $0.01^{2}$ & -0.091 & 0.034 & 5 \\
\hline Prob25 & $\begin{array}{l}\text { F: GATCCAGTGTGAAGCTAAAACAAGG } \\
\text { R: GTTTCTTAAGGTAGATGTGGAGTGTAG }\end{array}$ & $4.75(0.629)$ & $5.946^{9}$ & $0.113^{6}$ & $0.330^{6}$ & $0.691^{7}$ & $0.00^{1}$ & -0.028 & 0.695 & 6 \\
\hline Prob18 & $\begin{array}{l}\text { F: GATCATTGAGAACTATTTGGAAG } \\
\text { R: GTTTCTTATCAGTTGAACGCGAGAA }\end{array}$ & $4.25(0.479)$ & 510 & $0.112^{7}$ & $0.327^{7}$ & $0.694^{6}$ & $0.00^{1}$ & 0.035 & 0.198 & 7 \\
\hline Prob06 & $\begin{array}{l}\text { F: TCCAACCCACCTGAATTATCCAT } \\
\text { R: GTTTCTTAGCTCCAATTCCGGGCTCT }\end{array}$ & $6(1.414)$ & $7.957^{4}$ & $0.197^{9}$ & $0.213^{9}$ & $0.566^{9}$ & $0.00^{1}$ & -0.022 & 0.606 & 8 \\
\hline Prob09 & $\begin{array}{l}\text { F: GAACGTTTGTAGGGATAGTCCAC } \\
\text { R: GTTTCTTACCGTGTCCACCCCTTATTCG }\end{array}$ & $7.25(1.493)$ & $10.833^{2}$ & $0.199^{10}$ & $0.198^{10}$ & $0.56^{10}$ & $0.06^{6}$ & 0.146 & $0.003^{*}$ & 9 \\
\hline Prob15 & $\begin{array}{l}\text { F: GTGTCCCAGCCAGACCCAAT } \\
\text { R: TCAGGTGTCCTGTCTCTGCTTCC }\end{array}$ & $5.5(1.323)$ & 66 & $0.135^{8}$ & $0.303^{8}$ & $0.656^{8}$ & $0.186^{9}$ & 0.439 & $0^{*}$ & 10 \\
\hline Prob01 & $\begin{array}{l}\text { F: TGCTCCCCATTCTACAGGTC } \\
\text { R: TGTTTCCATAATTTGGCTTGC }\end{array}$ & $3(0.408)$ & $3.999^{14}$ & $0.207^{11}$ & $0.186^{11}$ & $0.559^{11}$ & $0.058^{5}$ & 0.129 & 0.016 & 11 \\
\hline Prob29 & $\begin{array}{l}\text { F: CAACACTGTGTATGCCCATGC } \\
\text { R: GTTTCTTGTTTGGACCCAGCAATCACC }\end{array}$ & $3.75(0.629)$ & 413 & $0.338^{13}$ & $0.108^{13}$ & $0.415^{13}$ & $0.00^{1}$ & -0.1 & 0.134 & 12 \\
\hline Prob34 & $\begin{array}{l}\text { F: GGTGCTGGAAGGTGGCTTCT } \\
\text { R: GCTTTGGCTGGTGGTCCATT }\end{array}$ & $4(0.408)$ & $4.999^{11}$ & $0.363^{14}$ & $0.095^{14}$ & $0.392^{14}$ & $0.00^{1}$ & -0.055 & 0.004 & 13 \\
\hline Prob28 & $\begin{array}{l}\text { F: GATCAAGGTATCATTAATAAGC } \\
\text { R: GAGCTCTCATTGTATGTCAA }\end{array}$ & $3(0.707)$ & $4.957^{12}$ & $0.28^{12}$ & $0.167^{12}$ & $0.475^{12}$ & $0.081^{7}$ & 0.14 & $0.001^{*}$ & 14 \\
\hline Prob35 & $\begin{array}{l}\text { F: ATTGCTGTATTGTGGGTAGG } \\
\text { R: GATCAGCTCTTCACAGGAAT }\end{array}$ & $2.5(0.5)$ & $3.995^{15}$ & $0.557^{15}$ & $0.034^{15}$ & $0.246^{15}$ & $0.00^{1}$ & 0.055 & 0.067 & 15 \\
\hline Prob36 & $\begin{array}{l}\text { F: GATCAAAAGCTATCTGACTGGACA } \\
\text { R: GTTTCTTCCATATTCTCATTTGCTTTC }\end{array}$ & $1.75(0.25)$ & 216 & $0.59^{16}$ & $0.032^{16}$ & $0.221^{16}$ & $0.125^{8}$ & 0.471 & $0.001^{*}$ & 16 \\
\hline Mean: & & $6.813(1.089)$ & $910(1.149)$ & - & - & $0.581(0.047)$ & $3.62(1.37)$ & 0.047 & - & \\
\hline
\end{tabular}




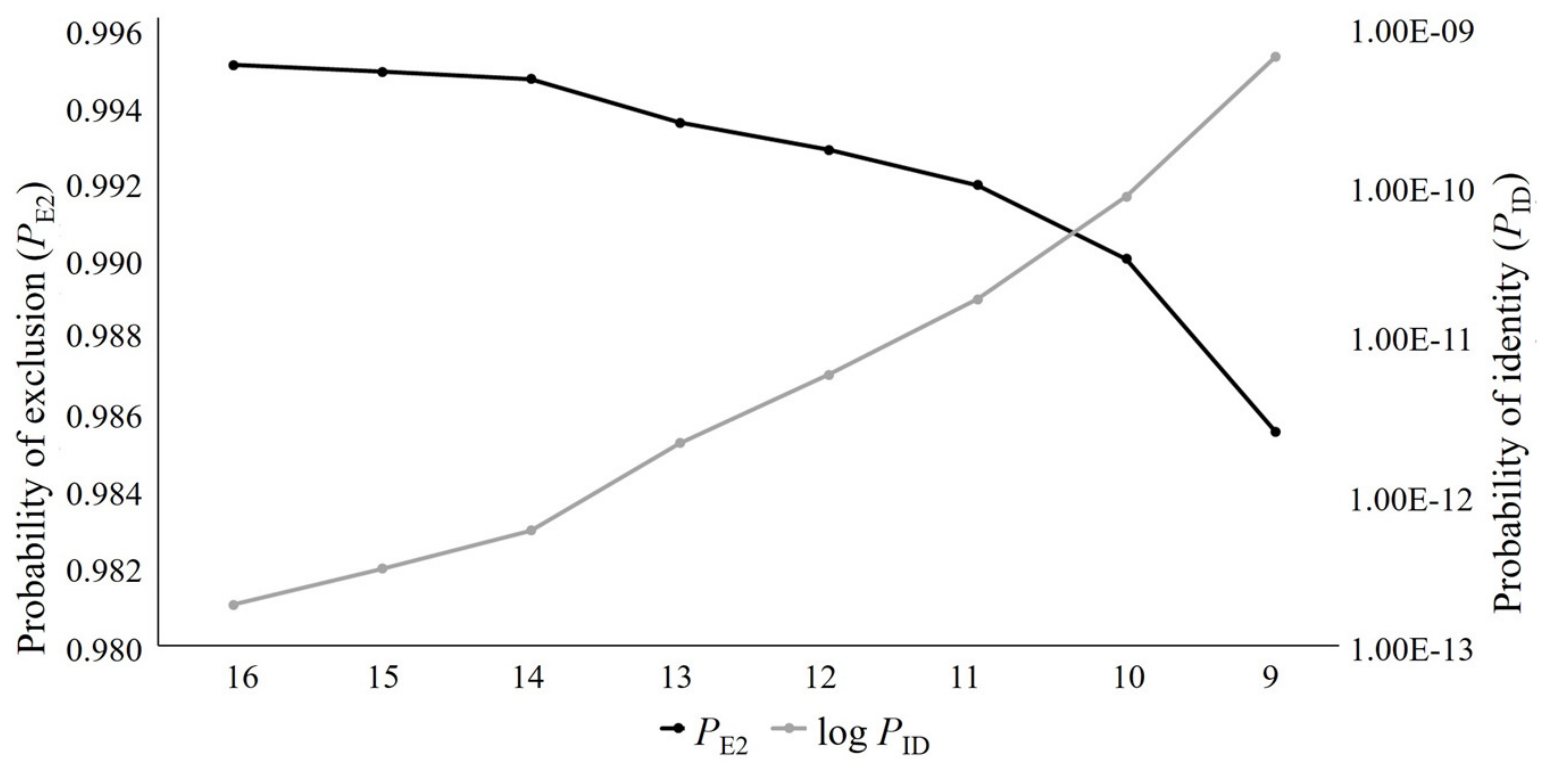

302

303 Figure 1. The $\log$ values of the probability of identity $\left(\log P_{\mathrm{ID}}\right)$ and probability of exclusion (one 304 parent known, $P_{\mathrm{E} 2}$ ) estimates for the eight microsatellite panels tested on the captive Poicephalus 305 robustus data set in the current study. It can be observed that the full 16 locus panel has the most 306 optimum $P_{\mathrm{ID}}$ and $P_{\mathrm{E} 2}$ values compared to the other seven panels tested in this study.

All eight microsatellite panels showed very low combined probability of identity values, with 309 moderate to high informativeness levels (PIC range: 0.581 to 0.703; Supplementary Table 4). The probability of identity values for the eight panels ranged from $1.8 \mathrm{E}-13$ for the 16 locus panel to 5.7E-10 for the 9 locus panel (Supplementary Table 3). These values suggest 1 in 5.5E+12 (16 loci) to $1.8 \mathrm{E}+9$ (9 loci) randomly chosen individuals will share the same genotype. The assessment from this parameter alone suggests that any of these panels could be suitable for forensic use, as the total number of wild Cape Parrots does not exceed 1600 individuals. The ability of these eight panels to successfully identify known parents, however, differed. The seven larger panels were generally equally successful in identifying parent pairs and individual parents,

317 with only slight differences in the mean probability values and a slightly higher sire

318 identification success rate for the 10 locus panel (Figure 2; Supplementary Table 4). The 9 locus 319 panel was less successful in correctly identifying parent pairs, with only $71 \%$ of parent pairs 320 correctly identified with high probability (probability $>0.75$ ). The 9 locus panel also showed a 
321 lower success rate at identifying the correct sires and dams, with $73.7 \%$ of sires and $96.8 \%$ of

322 dams correctly identified with high probability (probability $>0.75$ ). All known dams were

323 correctly identified using the seven larger panels. Although the seven larger panels had similar 324 assignment success rates (parent pair assignment success $=83.9 \%$ ), the full 16 locus panel had 325 overall higher mean probability rates making this panel most suited for use in future parentage 326 analyses. 


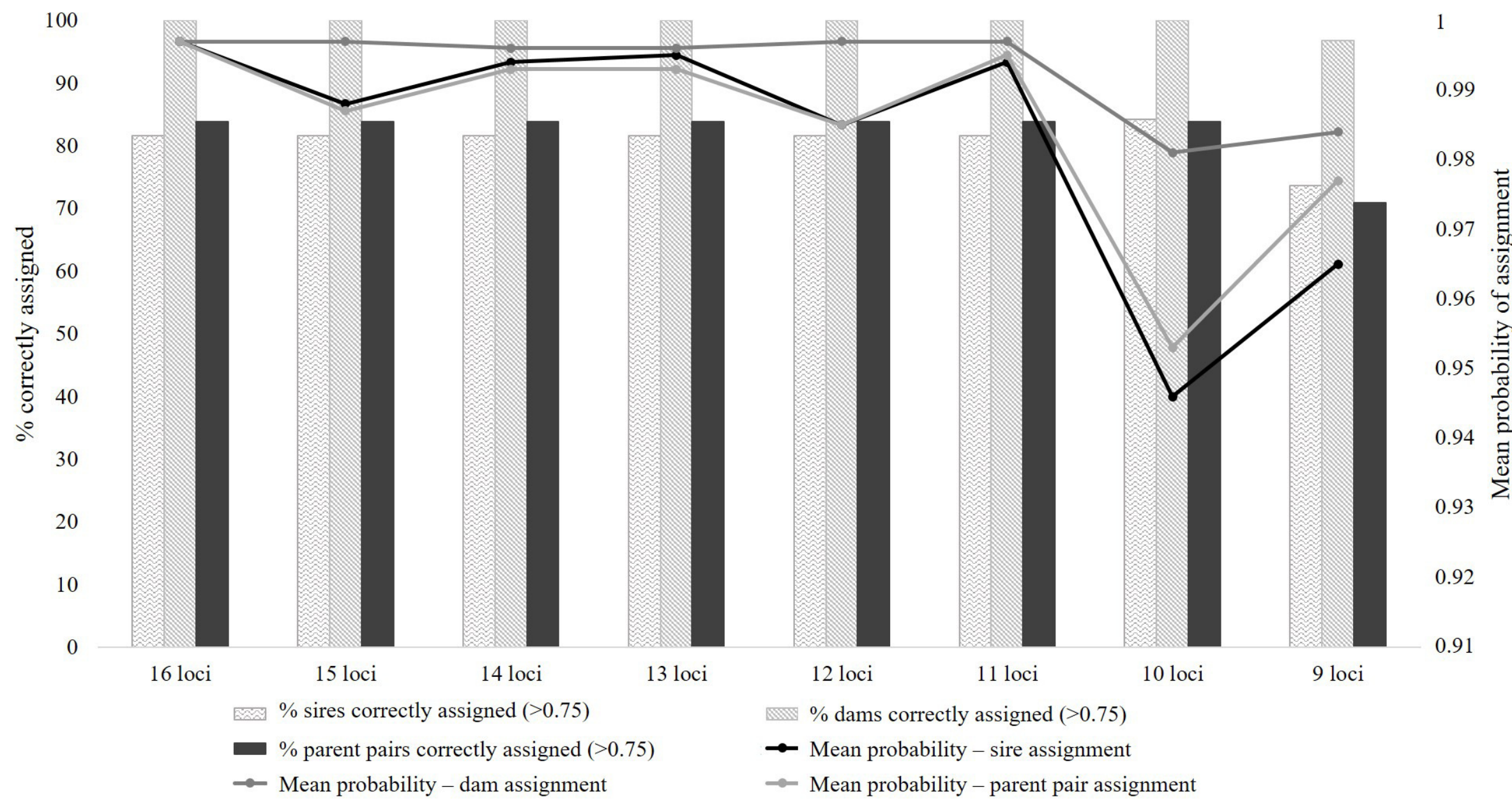

328 Figure 2. The parent pair and individual parentage assignment success of the eight microsatellite panels tested for use in Poicephalus robustus. The bars correspond to the percentage known parents correctly assigned to each offspring, with high probability; the lines are representative of the probability values for each assignment type. 
331

332 The majority of the test individuals were assigned to the correct population of origin following

333 the partial Bayesian exclusion analyses using the eight microsatellite panels (83.33\% to 66.67\%).

334 The highest assignment success was achieved with the six larger microsatellite panels (16 loci to

33511 loci), with $83.33 \%$ of the specimens correctly assigned (Figure 3; Supplementary Table 5).

336 The 12 locus panel had the best average assignment probability value out of the eight tested

337 panels (Average assignment probability $=0.565, \mathrm{SE}=0.087$ ), with five out of the 10 individuals

338

339

340

341

342

343

344

345

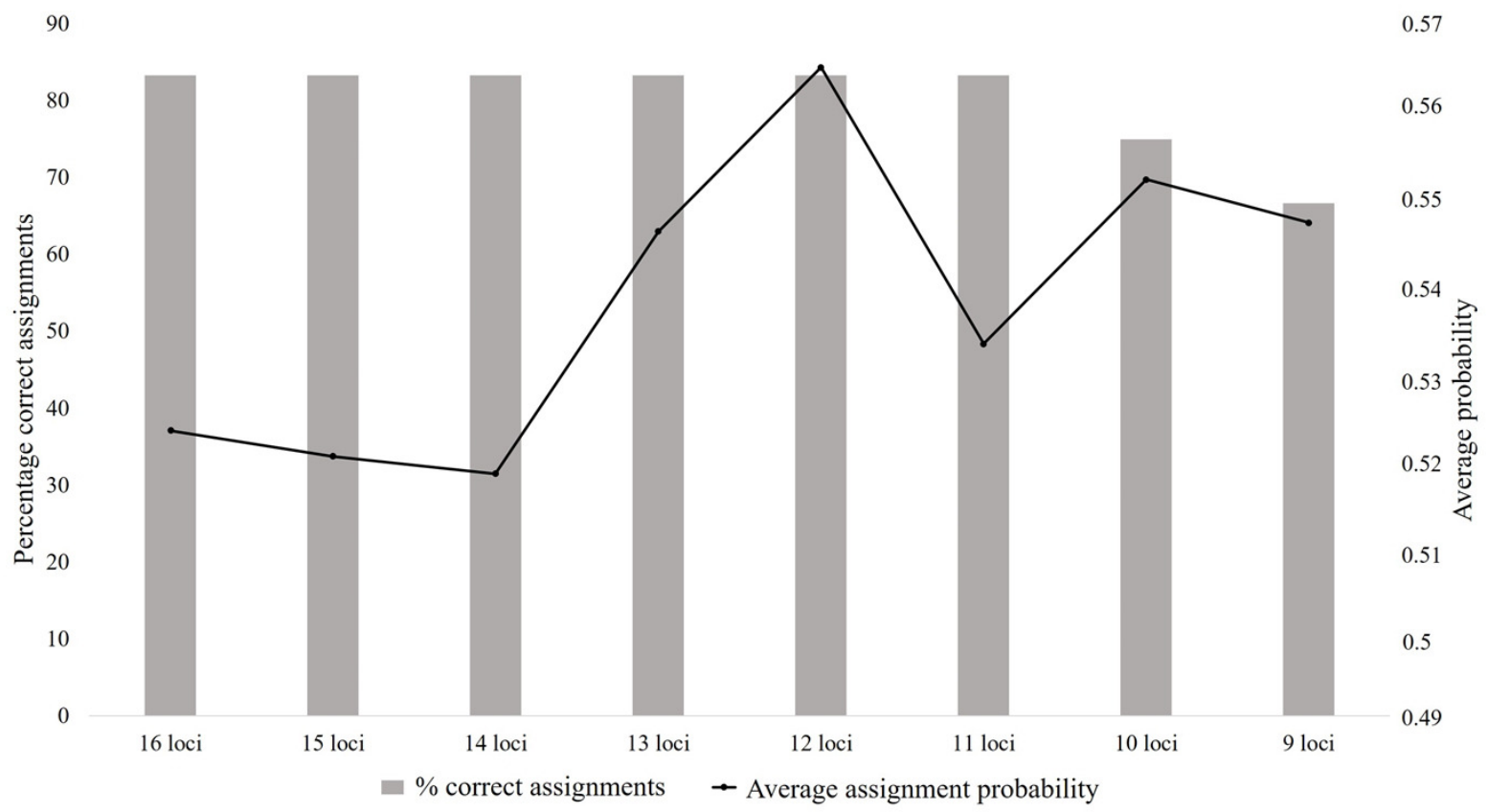
correctly assigned with assignment probabilities above 0.6 . The remaining five individuals assigned to the correct populations with assignment probabilities lower than 0.6 (assignment probability $=0.170-0.591$; Supplementary Table 5). The two individuals (FH12 and FH32) that were incorrectly assigned, were sampled from the Eastern Cape but assigned to the captive (FH12) and KZN (FH32) populations. The assignment probabilities of these individuals did, however, differ only slightly between the actual population of origin and the assigned population (Supplementary Table 5).
346 
349

350

351

352

353

354

355

356

357

358

359

360

361

362

363

364

365

366

367

368

369

370

371

372

373

374

375

376

377

378

origin. The black line represents the average assignment probability calculated from the correctly assigned specimens' probability values. The exact probability values for the assignments conducted with each of the eight panels are available in Supplementary Table 5.

\section{Genetic diversity: captive versus wild populations}

The genetic diversity estimates for the captive data set, using 16 microsatellite loci, was largely similar to that observed for the wild Cape Parrot populations (Table 2). Significant differences were observed between the Captive/Central and Captive/North per locus Na estimates ( $p$-value $<$ $0.003)$. The average number of alleles observed for the captive data set was higher than that observed in the wild population (captive, $N_{\mathrm{A}}=6.813$, southern, $N_{\mathrm{A}}=6.563$; central, $N_{\mathrm{A}}=5.313$; northern, $N_{\mathrm{A}}=2.875$; Table 2). The significant differences observed for the Na estimates could, however, be influenced by differences in sample size (Captive born samples, $\mathrm{n}=71$; South, $\mathrm{n}=$ 60; Central, $n=20$; North, $n=5$ ). The allelic richness (Ar) estimates provide a more accurate estimation, with no significant difference observed among the Captive and wild per locus Ar estimates ( $p$-value $<0.003$ ). The captive data set did, however, have the highest number of private alleles $\left(\mathrm{P}_{\mathrm{A}}=21\right)$, which was almost double that of the highest value observed among the wild populations (southern, $\mathrm{P}_{\mathrm{A}}=13$ ). All private alleles occurred at low frequencies, with private allele frequencies for the captive data set ranging from 0.007 to 0.100 and frequencies for the southern wild population ranging from 0.008 to 0.133 . No significant differences were observed between the Captive vs wild per locus observed heterozygosity $\left(H_{\mathrm{O}}\right)$, unbiased expected heterozygosity $\left(u H_{\mathrm{E}}\right)$ and inbreeding coefficient $\left(F_{\mathrm{IS}}\right)$ comparisons.

The $\mathrm{H}_{\mathrm{O}}$ for the captive data set was only slightly lower than that observed for the three wild populations (captive, $H_{\mathrm{O}}=0.591$; southern, $H_{\mathrm{O}}=0.605$; central, $H_{\mathrm{O}}=0.647$; northern, $H_{\mathrm{O}}=$ 0.6), with an $u H_{\mathrm{E}}$ comparable to that observed for the South and Central wild populations (captive, $u H_{\mathrm{E}}=0.625$; southern, $u H_{\mathrm{E}}=0.632$; central, $u H_{\mathrm{E}}=0.635$ ). A low positive $F_{\text {IS }}$ value was observed for the captive data set indicated only slight inbreeding $\left(F_{\text {IS }}=0.054\right)$, with low heterozygote deficiency. Low genetic differentiation was found only between the captive data set and the South population $\left(F_{\mathrm{ST}}=0.017 ; p\right.$-value $\left.=0.001\right)$. No significant genetic differentiation was observed between the captive and North populations $\left(F_{\mathrm{ST}}=0.104 ; p\right.$-value $\left.=0.004\right)$ or the captive and Central populations $\left(F_{\mathrm{ST}}=0.01 ; p\right.$-value $\left.=0.024\right)$, following a Bonferroni correction ( $p$-value $=0.003)$. The global $F_{\mathrm{ST}}$ value calculated for the captive and three wild populations did 
379 not significantly differ from zero $\left(F_{\mathrm{ST}}=0.008 ; p\right.$-value $\left.=0.008\right)$. The analysis of molecular 380 variance (AMOVA) indicated that $92 \%$ of the observed genetic variance occurred within 381 individuals, with $5 \%$ of the genetic variance between individuals and only $3 \%$ among the 382 populations.

383 Table 2. The genetic diversity estimates for each of the wild Poicephalus robustus populations 384 and the captive data set, using 16 microsatellite loci. Standard error for average number of 385 alleles, observed heterozygosity and unbiased expected heterozygosity is provided in 386 parentheses.

\begin{tabular}{|c|c|c|c|c|c|c|}
\hline Locality: & $\begin{array}{c}\text { Average } \\
\text { number of } \\
\text { alleles }\left(N_{\mathrm{A}}\right) \text { : }\end{array}$ & $\begin{array}{l}\text { Allelic richness } \\
\text { (Ar): }\end{array}$ & $\begin{array}{c}\text { Observed } \\
\text { heterozygosity } \\
\left(H_{\mathrm{O}}\right) \text { : }\end{array}$ & $\begin{array}{c}\text { Unbiased } \\
\text { expected } \\
\text { heterozygosity } \\
\left(u H_{\mathrm{E}}\right):\end{array}$ & $\begin{array}{c}\text { Inbreeding } \\
\text { coefficient } \\
\left(F_{\text {IS }}\right)\end{array}$ & $\begin{array}{l}\text { Private alleles } \\
\qquad\left(\mathrm{P}_{\mathrm{A}}\right):\end{array}$ \\
\hline
\end{tabular}

\begin{tabular}{|c|c|c|c|c|c|c|}
\hline South & $6.563(1.252)$ & $3.791(0.400)$ & $0.605(0.055)$ & $0.632(0.053)$ & 0.042 & 13 \\
\hline Central & $5.313(0.898)$ & $3.708(0.386)$ & $0.647(0.058)$ & $0.635(0.05)$ & -0.02 & 5 \\
\hline North & $2.875(0.34)$ & $2.875(0.340)$ & $0.6(0.063)$ & $0.572(0.052)$ & -0.055 & 2 \\
\hline Captive & $6.813(1.089)$ & $3.673(0.314)$ & $0.591(0.065)$ & $0.625(0.047)$ & 0.054 & 21 \\
\hline
\end{tabular}

\section{Discussion}

\section{Microsatellite evaluation}

390 The high LD levels observed in the current study was, however, not observed during the 391 phylogeographic analysis of Cape Parrots by Coetzer (2015). This could be explained by the 392 population history of the captive population, as admixture, rapid population expansion, 393 bottleneck events and genetic drift can affect LD (Rogers 2014). The selection of a suitable locus 394 combination was therefore not based on these LD estimates. The null allele frequencies and 395 expected heterozygosity values observed for the loci from the current study is generally 396 comparable to that reported by Pillay et al. (2010). The majority of these loci were highly to moderately informative, following the current study. The allelic richness values from the current 
398 study only marginally deviated from the allele numbers reported by Pillay et al. (2010). Locus

399 Prob15 was previously reported as Z-linked in Cape Parrots (Pillay et al. 2010). Two of the

400 known females for the current study were, however, heterozygous at this locus. The same trend

401 was observed by Taylor (2011) who found no evidence of sex linkage of Prob15 in other

402 Poicephalus species, including P. fuscicollis fuscicollis and P. f. suahelicus. The level of

403 variation and informativeness observed in the current study is comparable to that observed in

404 other studies. The PIC values observed in the current study falls within the same range as the

405 values observed by Klauke et al. (2013) during a study investigating the breeding system of the

406 endangered El Oro parakeet from southwest Ecuador. The combined $\mathrm{P}_{\mathrm{ID}}$ observed by Russello et

407 al. (2007) for 14 loci used in the South American Monk parakeet was lower than that observed

408 for Cape Parrots in the current study.

409

410

411

412

413

414

415

416

417

418

419

420

421

422

423

424

425

426

427

\section{Microsatellite loci for parentage analysis}

The locus informativeness analyses performed on the 16 microsatellite loci, allowed for the ranking of the 16 loci according to their level of informativeness. The full locus set of 16 markers showed to be the best combination of markers for parentage analysis, of the eight panels tested. This panel had the highest average assignment probabilities for parent pair, sire and dam assignment tests (Figure 2). This panel is highly suited for individual-level identification, with a probability of identity value suggesting that 1 in $5.5 \mathrm{E}+12$ individuals will share the same genotype. All the known dams were positively identified with this panel, but only 31 of the 38 offspring's known sires were identified with high probability. It was observed that the 10 locus panel did have a better assignment rate for the known sires, with 32 of the 38 sires identified, but the average assignment probability value was much lower than that observed for the 16 locus panel (Figure 2). Similar success rates were observed by Labuschagne et al. (2015) when assessing the utility of 12 microsatellite loci for parentage assignment in the African Penguin (Spheniscus demersus). The failure to assign a parent, or assignment of a parent with low probability, can be linked to the occurrence of amplification errors during PCR causing allelic dropout, null alleles, stuttering or polymerase slippage (Buckleton et al. 2005; Dewoody et al. 2006; Ferrie et al. 2013). It is possible to compensate for such errors in the parentage analysis program Colony by importing the expected error rates of each locus, including null allele frequencies, prior to analysis. When this was done in the current study, failed or incorrect 
428

429

430

431

432

433

434

435

436

437

438

439

440

441

442

443

444

445

446

447

448

449

450

451

452

453

454

455

456

assignments were still observed and it is advisable to not only rely on genetic data, but also make use of a complete studbook of legally registered captive bred birds, as suggested by Ferrie et al. (2013). It is therefore important to compile a complete studbook of all captive bred Cape Parrots, complemented by a complete DNA data base using the full 16 locus microsatellite panel described in this study. The inclusion of additional markers such as single nucleotide polymorphisms (SNPs) can improve the success rate of the parentage analysis, as demonstrated in (Labuschagne et al. 2015).

\section{Population of origin analysis}

The assignment analysis performed with six of the eight microsatellite panels (16 loci to 11 loci) all had a success rate of $83.33 \%$. The average assignment probabilities of the correct assignments did however differ, with the 12 locus panel outperforming the rest (Figure 3). The two Eastern Cape individuals were not assigned to their population of origin, with sample FH12 assigned to the Captive population and FH32 assigned to KZN (Supplementary Table 5). The probabilities that these two samples should be assigned to the Captive and KZN populations were only marginally higher than the probabilities observed for assignment to the Eastern Cape population. This could be due to the occurrence of ancestral admixture, as it is shown that the southern (Eastern Cape) populations form a source to the central (KZN) populations (Coetzer 2015), and the captive bred populations in turn is largely sourced from the KZN populations (C.T. Downs unpublished data). These individuals could therefore have ancestral links to individuals in the central $(\mathrm{KZN})$ and the captive populations (via the KZN populations).

\section{Captive vs Wild Cape Parrots}

The majority of the genetic differentiation estimates showed little to no genetic difference between the captive data set and the three wild Cape Parrot populations. Similar AMOVA results were observed in a study focusing purely on the genetic variation among the wild Cape Parrot populations (Coetzer 2015). A clear difference was, however, observed for the private allele estimate. The captive data set contained almost double the number of private alleles observed in the southern wild population, which the recent phylogeographic study suggests is the most genetically diverse wild population (Coetzer 2015). In theory, the higher number of private alleles in the captive population could be due to rare alleles, which are generally not often seen in 
457 the wild, being present in the founders of the captive populations. Gautschi et al. (2003) observed

458 a similar trend in a captive bearded vulture (Gypaetus barbatus) population, with a higher level

459 of genetic diversity in the captive population when compared to that observed in the wild

460 population. This was linked to founder individuals, who are still present in the breeding

461 population, carrying rare alleles and thereby passing these alleles down to their offspring

462 (Gautschi et al. 2003). It is therefore possible that the captive Cape Parrots have not been in

463 captivity for an appropriate amount of time to lose the observed rare alleles, and that these alleles

464 are still being passed down to the new generations. New wild birds are also regularly introduced

465 to the captive stock, through the addition of injured or confiscated wild birds (Wilkinson 2015).

466 These introductions could then also supplement the genetic diversity of the captive population,

467 especially if the birds originate from different regions of the Cape Parrot's natural distribution

468 range. Many of the birds in the captive data set used in the current study are F1 to F3

469 descendants from wild birds, and could therefore still carry these rare alleles.

470

471

472

473

474

475

476

477

478

479

480

481

482

483

484

485

486

The captive and wild birds are also subjected to different environmental forces, which can lead to genetic adaptation to captivity (Frankham 2008). The difference in selective pressures such as a lack of predators, food availability and pathogenic exposure could promote the selection of certain traits in captive animals, which would normally be detrimental in the wild (Lynch \& O'Hely 2001). It is possible for selection of certain rare, fitness linked, loci to influence the genetic diversity of neutral loci like microsatellites, although it was observed to mostly decrease the genetic diversity of neutral loci (Montgomery et al. 2010). It could, therefore, also be argued that the large number of private alleles observed in the captive sample set could in some way be linked to the selection of rare alleles, due to human mediated mate selection of breeding pairs. Further analyses using fitness linked loci, like the major histocompatibility complex (MHC) genes or toll like receptor (TLR) genes, should be performed to better understand the effects captive breeding has on the genetic health of the Cape Parrot population.

\section{Conclusion}

The assessment of the 16 microsatellite loci tested in the current study identified the full 16 locus panel as the best set of markers for use in parentage analysis. Such analyses should be performed on traded birds suspected of being illegally harvested from the wild. It is therefore important to 
487 have a data base of all legally owned Cape Parrots and a complete studbook for future use. Using

488 this set of loci, birds suspected of being illegally harvested from the wild can be traced to region 489 of origin through implementation of the partial Bayesian approach in GeneClass 2 for individual 490 assignment analysis. The 12 locus microsatellite panel is most appropriate for this analysis. It is, 491 however, recommended to increase the reference data sets, for both the wild and captive 492 populations, thereby increasing the accuracy of the individual assignment analysis using the 493 assignment methods implemented in GeneClass2. This recommendation is based on the low 494 level of differentiation observed between the wild and captive populations. The use of additional 495 highly polymorphic loci could improve these results (Cornuet et al. 1999). The high number of 496

497 498 499 500 501

502 503 504 505 506 507 508 509 private alleles observed in the captive population highlights its distinctiveness. Reintroductions to the wild from the current captive population is not recommended until further analyses of fitness related loci are performed, as accumulation of certain rare alleles could have detrimental effects on the wild populations. It is further recommended that, for reintroduction purposes, captive populations from the three Cape Parrot populations should be kept separate to prevent unnatural admixture of the different genetic groups.

The results from this study will help conservation and law enforcement authorities to better police and identify cases of illegal trafficking in South Africa's only endemic parrot. The information obtained here also highlights the genetic distinctiveness of the captive population, and the effect these birds will have on wild populations should be considered before any future re-introductions plans are made.

\section{Acknowledgements}

The researchers would like to thank all the private Cape Parrot breeders for their support in providing samples for this study; Mr. W. Horsfield (Amazona Birds Cc), Mr T. Davies and Mrs L. Davies (private breeders) and Mr S. Wilkinson (Montecasino Bird Gardens, Johannesburg).

\section{References}

Alacs EA, Georges A, FitzSimmons NN, and Robertson J. 2010. DNA detective: a review of molecular approaches to wildlife forensics. Forensic Science, Medicine, and Pathology 6:180-194. $10.1007 / \mathrm{s} 12024-009-9131-7$ 
517
Bergner L, Jamieson I, and Robertson B. 2014. Combining genetic data to identify relatedness among founders in a genetically depauperate parrot, the Kakapo (Strigops habroptilus). Conservation Genetics:1-8. 10.1007/s10592-014-0595-y

Botstein D, White RL, Skolnick M, and Davis RW. 1980. Construction of a genetic linkage map in man using restriction fragment length polymorphisms. American Journal of Human Genetics 32:314.

Boyce WM, Weisenberger ME, Penedo MCT, and Johnson CK. 2011. Wildlife translocation: the conservation implications of pathogen exposure and genetic heterozygosity. BMC Ecology 11:5.

Broad S, Mulliken T, and Roe D. 2002. The nature and extent of legal and illegal trade in wildlife. In: Oldfield S, ed. The trade in wildlife: regulation for conservation. London: Earthscan Publications Ltd., 3-22.

Buckleton JS, Triggs CM, and Walsh SJ. 2005. Forensic DNA evidence interpretation. Boca: CRC press.

Bush ER, Baker SE, and Macdonald DW. 2014. Global Trade in Exotic Pets 2006-2012. Conservation Biology 28:663-676. 10.1111/cobi.12240

Chapuis M-P, and Estoup A. 2007. Microsatellite null alleles and estimation of population differentiation. Molecular Biology and Evolution 24:621-631.

Coetzer WG. 2015. Systematics and Phylogeography of the Cape Parrot (Poicephalus robustus) PhD. University of KwaZulu-Natal.

Coetzer WG, Downs CT, Perrin MR, and Willows-Munro S. 2015. Molecular Systematics of the Cape Parrot (Poicephalus robustus): Implications for Taxonomy and Conservation. PLoS ONE 10:e0133376. 10.1371/journal.pone.0133376

Coghlan ML, White NE, Parkinson L, Haile J, Spencer PB, and Bunce M. 2012. Egg forensics: an appraisal of DNA sequencing to assist in species identification of illegally smuggled eggs. Forensic Science International: Genetics 6:268-273. 10.1016/j.fsigen.2011.06.006

Comstock KE, Ostrander EA, and Wasser SK. 2003. Amplifying nuclear and mitochondrial DNA from African elephant ivory: a tool for monitoring the ivory trade. Conservation Biology 17:18401843. 10.1111/j.1523-1739.2003.00358.x

Cooney R, and Jepson P. 2006. The international wild bird trade: what's wrong with blanket bans? Oryx 40:18-23. 10.1017/S0030605306000056

Cornuet JM, Piry S, Luikart G, Estoup A, and Solignac M. 1999. New methods employing multilocus genotypes to select or exclude populations as origins of individuals. Genetics 153:1989-2000.

Dakin EE, and Avise JC. 2004. Microsatellite null alleles in parentage analysis. Heredity 93:504-509. 10.1038/sj.hdy.6800545

Dawnay N, Ogden R, Wetton JH, Thorpe RS, and McEwing R. 2009. Genetic data from 28 STR loci for forensic individual identification and parentage analyses in 6 bird of prey species. Forensic Science International: Genetics 3:e63-e69. 10.1016/j.fsigen.2008.07.001

Dewoody J, Nason JD, and Hipkins VD. 2006. Mitigating scoring errors in microsatellite data from wild populations. Molecular Ecology Notes 6:951-957. 10.1111/j.1471-8286.2006.01449.x

Downs CT, Pfeiffer M, and Hart LA. 2014. Fifteen years of annual Cape Parrot Poicephalus robustus censuses: current population trends and conservation contributions. Ostrich 85:273-280. 10.2989/00306525.2014.959088

Ferrie GM, Cohen OR, Schutz P, Leighty KA, Plasse C, Bettinger TL, and Hoffman EA. 2013. Identifying parentage using molecular markers: Improving accuracy of studbook records for a captive flock of marabou storks (Leptoptilus crumeniferus). Zoo Biology 32:556-564. 10.1002/zoo.21090

Frankham R. 2008. Genetic adaptation to captivity in species conservation programs. Molecular Ecology 17:325-333. 10.1111/j.1365-294X.2007.03399.x

Fung WK, Chung Y, and Wong D. 2002. Power of exclusion revisited: probability of excluding relatives of the true father from paternity. International Journal of Legal Medicine 116:64-67. $10.1007 / \mathrm{s} 004140100210$ 
566

Gautschi B, Müller J, Schmid B, and Shykoff J. 2003. Effective number of breeders and maintenance of genetic diversity in the captive bearded vulture population. Heredity 91:9-16. 10.1038/sj.hdy.6800278

Gonçalves PFM, Oliveira-Marques AR, Matsumoto TE, and Miyaki CY. 2015. DNA barcoding identifies illelgal parrot trade. Jounal of Heredity 106:560-564. 10.1093/jhered/esv035

Goudet J. 2001. FSTAT, a program to estimate and test gene diversities and fixation indices (version 2.9.3). Available at http://www.unil.ch/zea/softwares/fstat.html.

Grobler JP, Kotze A, Swart H, and Hallerman EM. 2005. The application of microstellite DNA markers for forensic analysis of koi carp (Cyprinus carpio): research in action. South African Journal of Science 101:19-21.

Gupta SK, Verma SK, and Singh L. 2005. Molecular insight into a wildlife crime: the case of a peafowl slaughter. Forensic Science International 154:214-217. 10.1016/j.forsciint.2004.12.010

Hindar K, Ryman N, and Utter F. 1991. Genetic effects of cultured fish on natural fish populations. Canadian Journal Of Fish and Aquatic Science 48:945-957. 10.1139/f91-111

Interpol. 2014. Illegal trade in wildlife and timber products finances criminal and militia groups, threatening security and sustainable development. Available at http://www.interpol.int/News-andmedia/News/2014/N2014-119 (accessed 20 August 2015).

Johnson MS. 2000. Measuring and interpreting genetic structure to minimize the genetic risks of translocations. Aquaculture Research 31:133-143.

Jones OR, and Wang J. 2010. COLONY: a program for parentage and sibship inference from multilocus genotype data. Molecular Ecology Resources 10:551-555. 10.1111/j.1755-0998.2009.02787.x

Kalinowski ST, Taper ML, and Marshall TC. 2007. Revising how the computer program CERVUS accommodates genotyping error increases success in paternity assignment. Molecular Ecology 16:1099-1106.

Klauke N, Segelbacher G, and Schaefer HM. 2013. Reproductive success depends on the quality of helpers in the endangered, cooperative El Oro parakeet (Pyrrhura orces). Molecular Ecology 22:2011-2027.

Labuschagne C, Nupen L, Kotzé A, Grobler PJ, and Dalton DL. 2015. Assessment of microsatellite and SNP markers for parentage assignment in ex situ African Penguin (Spheniscus demersus) populations. Ecology and Evolution 5:4389-4399. 10.1002/ece3.1600

Li L, and Jiang Z. 2014. International Trade of CITES Listed Bird Species in China. PLoS ONE 9:e85012.

Lorenzini R. 2005. DNA forensics and the poaching of wildlife in Italy: A case study. Forensic Science International 153:218-221. http://dx.doi.org/10.1016/j.forsciint.2005.04.032

Lorenzini R, Cabras P, Fanelli R, and Carboni GL. 2011. Wildlife molecular forensics: identification of the Sardinian mouflon using STR profiling and the Bayesian assignment test. Forensic Science International: Genetics 5:345-349. 10.1016/j.fsigen.2011.01.012

Loughnan SR, Smith-Keune C, Jerry DR, Beheregaray LB, and Robinson NA. 2015. Genetic diversity and relatedness estimates for captive barramundi (Lates calcarifer, Bloch) broodstock informs efforts to form a base population for selective breeding. Aquaculture Research. 10.1111/are.12807

Lynch M, and O'Hely M. 2001. Captive breeding and the genetic fitness of natural populations. Conservation Genetics 2:363-378.

Lyons JA, and Natusch DJD. 2011. Wildlife laundering through breeding farms: Illegal harvest, population declines and a means of regulating the trade of green pythons (Morelia viridis) from Indonesia. Biological Conservation 144:3073-3081. http://dx.doi.org/10.1016/j.biocon.2011.10.002

Manel S, Berthier P, and Luikart G. 2002. Detecting wildlife poaching: identifying the origin of individuals with Bayesian assignment tests and multilocus genotypes. Conservation Biology 16:650-659. 
616

617

618

619

620

621

622

623

624

625

626

627

628

629

630

631

632

633

634

635

636

637

638

639

640

641

642

643

644

645

646

647

648

649

650

651

652

653

654

655

656

657

658

659

660

661

662

663

664

665

666

Martin RO, Perrin MR, Boyes RS, Abebe YD, Annorbah ND, Asamoah A, Bizimana D, Bobo KS, Bunbury N, and Brouwer J. 2014. Research and conservation of the larger parrots of Africa and Madagascar: a review of knowledge gaps and opportunities. Ostrich 85:205-233.

Masello JF, Sramkova A, Quillfeldt P, Epplen JT, and Lubjuhn T. 2002. Genetic monogamy in burrowing parrots Cyanoliseus patagonus? Journal of Avian Biology 33:99-103.

Mateescu R, Zhang Z, Tsai K, Phavaphutanon J, Burton-Wurster N, Lust G, Quaas R, Murphy K, Acland GM, and Todhunter RJ. 2005. Analysis of allele fidelity, polymorphic information content, and density of microsatellites in a genome-wide screening for hip dysplasia in a crossbreed pedigree. Journal of Heredity 96:847-853.

Mondol S, Sridhar V, Yadav P, Gubbi S, and Ramakrishnan U. 2014. Tracing the geographic origin of traded leopard body parts in the indian subcontinent with DNA-based assignment tests.

Conservation Biology 29:556-564. 10.1111/cobi.12393

Montgomery ME, Woodworth LM, England PR, Briscoe DA, and Frankham R. 2010. Widespread selective sweeps affecting microsatellites in Drosophila populations adapting to captivity: Implication for captive breeding programs. Biological Conservation 143:1842-1849.

Nogueira SS, and Nogueira-Filho SL. 2011. Wildlife farming: an alternative to unsustainable hunting and deforestation in Neotropical forests? Biodiversity and Conservation 20:1385-1397.

Ogden R, and Linacre A. 2015. Wildlife forencis science: A review of genetic geogrphic origin assignment. Forensic Science International 18:152-159.

Paetkau D, Slade R, Burden M, and Estoup A. 2004. Genetic assignment methods for the direct, real-time estimation of migration rate: a simulation-based exploration of accuracy and power. Molecular Ecology 13:55-65.

Pain D, Martins T, Boussekey M, Diaz S, Downs C, Ekstrom J, Garnett S, Gilardi J, McNiven D, and Primot P. 2006. Impact of protection on nest take and nesting success of parrots in Africa, Asia and Australasia. Animal Conservation 9:322-330.

Peakall R, and Smouse PE. 2012. GenAlEx 6.5: genetic analysis in Excel. Population genetic software for teaching and research-an update. Bioinformatics 28:2537-2539.

Pillay K, Dawson DA, Horsburgh GJ, Perrin MR, Burke T, and Taylor TD. 2010. Twenty-two polymorphic microsatellite loci aimed at detecting illegal trade in the Cape parrot, Poicephalus robustus (Psittacidae, AVES). Mol Ecol Resour 10:142-149.

Pires SF. 2012. The illegal parrot trade: a literature review. Global Crime 13:176-190.

Piry S, Alapetite A, Cornuet JM, Paetkau D, Baudouin L, and Estoup A. 2004. GeneClass2: a software for genetic assignment and first-generation migrant detection. Journal of Heredity 95:536-539. 10.1093/jhered/esh074

Presti FT, Guedes NM, Antas PT, and Miyaki CY. 2015. Population genetic structure in Hyacinth Macaws (Anodorhynchus hyacinthinus) and identification of the probable origin of confiscated individuals. Journal of Heredity 106:491-502.

Primmer CR, Koskinen MT, and Piironen J. 2000. The one that did not get away: individual assignment using microsatellite data detects a case of fishing competition fraud. Proceedings of the Royal Society of London B: Biological Sciences 267:1699-1704. 10.1098/rspb.2000.1197

Pruett CL, Turner TN, Topp CM, Zagrebelny SV, and Winker K. 2010. Divergence in an archipelago and its conservation consequences in Aleutian Island rock ptarmigan. Conservation Genetics 11:241248. 10.1007/s10592-009-0026-7

Rannala B, and Mountain JL. 1997. Detecting immigration by using multilocus genotypes. Proceedings of the National Academy of Sciences 94:9197-9201.

Rice W. 1986. Analyzing tables of statistical tests. Evolution 1:223-225.

Riehl C. 2012. Mating system and reproductive skew in a communally breeding cuckoo: hard-working males do not sire more young. Animal Behaviour 84:707-714.

Robert A. 2009. Captive breeding genetics and reintroduction success. Biological Conservation 142:2915-2922.

Rogers AR. 2014. How population growth affects linkage disequilibrium. Genetics 197:1329-1341. 
667

Rosenberg NA, Li LM, Ward R, and Pritchard JK. 2003. Informativeness of Genetic Markers for Inference of Ancestry. The American Journal of Human Genetics 73:1402-1422. http://dx.doi.org/10.1086/380416

Rousset F. 2008. genepop'007: a complete re-implementation of the genepop software for Windows and Linux. Molecular Ecology Resources 8:103-106.

Russello M, Saranathan V, BUHRMAN-DEEVER S, Eberhard J, and Caccone A. 2007. Characterization of polymorphic microsatellite loci for the invasive monk parakeet (Myiopsitta monachus). Molecular Ecology Notes 7:990-992.

Storfer A. 1999. Gene flow and endangered species translocation: a topic revisited. Biological Conservation 87:173-180.

Taberlet P, and Luikart G. 1999. Non-invasive genetic sampling and individual identification. Biological Journal of the Linnean Society 68:41-55. 10.1111/j.1095-8312.1999.tb01157.x

Taylor M. 2014. Eskom Red data book of birds of South Africa, Lesotho and Swaziland. Birdlife South Africa, Johannesburg.

Taylor TD. 2011. Cross-utility of microsatellite markers across species of the African Poicephalus parrots to encourage conservation research. Ostrich 82:65-70.

TRAFFIC. 2008. Our Work: wildlife trade. Available at http://www.traffic.org/trade/ (accessed 23 November 2015).

Vallone PM, and Butler JM. 2004. AutoDimer: a screening tool for primer-dimer and hairpin structures. Biotechniques 37:226-231.

Waits LP, Luikart G, and Taberlet P. 2001. Estimating the probability of identity among genotypes in natural populations: cautions and guidelines. Molecular Ecology 10:249-256.

Wang J. 2004. Sibship Reconstruction From Genetic Data With Typing Errors. Genetics 166:1963-1979. 10.1534/genetics.166.4.1963

Warchol GL. 2004. The transnational illegal wildlife trade. Criminal Justice Studies 17:57-73.

White NE, Dawson R, Coghlan ML, Tridico SR, Mawson PR, Haile J, and Bunce M. 2012. Application of STR markers in wildlife forensic casework involving Australian black-cockatoos (Calyptorhynchus spp.). Forensic Science International: Genetics 6:664-670.

Wilkinson S. 2015. Regional Studbook: Cape Parrot Studbook (Poicephalus robustus). Montecasino Bird Gardens (under the auspices of PAAZA).

Williams SE, and Hoffman EA. 2009. Minimizing genetic adaptationin captive breeding programs: A review. Biological Conservation 142:2388-2400.

Wirminghaus JO. 1997. Cape Parrot Poicephalus robustus. In: Harrison JA, Alan DG, Underhill LL, Herremans M, Tree AJ, Parker V, and Brown CJ, eds. The Atlas of Southern African Birds. Johannesburg: BirdLife South Africa.

Wirminghaus JO, Downs CT, Symes CT, and Perrin MR. 1999. Conservation of the Cape parrot in southern Africa. South African Journal of Wildlife Research 29:118-129.

Wynberg R. 2002. A decade of biodiversity conservation and use in South Africa: tracking progress form the Rio Earth Summit to the Johannesburg World Summit on Sustainable Development: review article. South African Journal of Science 98:233-243. 